\title{
Insulin Therapy and Cardiovascular Outcome Trials (CVOTs): Any Harm, Anytime?
}

\author{
Uche Anyanwagu $^{1 *}$ and Ifeoma Ezegbulam ${ }^{2}$ \\ ${ }^{1}$ University of Nottingham, Royal Derby Hospital centre, UK \\ ${ }^{2}$ Adonai Hospitals, Lagos, Nigeria
}

*Corresponding author: Uche Anyanwagu, Division of Graduate Entry Medicine, School of Medicine, Derby, University of Nottingham, Royal Derby Hospital, UK

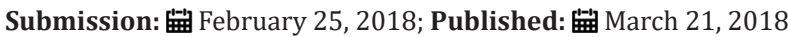

\section{Background}

The therapeutic management of diabetes may on its own increase the risk of cardiovascular (CV) risk markers - directly or indirectly - through their pharmacological actions (e.g. side effects as hypoglycaemia), or some metabolic changes (e.g. weight-gain, increased BP, etc.). As these risks may not have been anticipated or immediately noticed during clinical trials, 1 post hoc analyses and epidemiological follow up of clinical trials have raised concerns about the CV safety of some drugs used in the management of diabetes.

Of great popularity among all glucose lowering agents (GLTs) is insulin, which Alvarez et al described as the "the most potent anti-hyperglycaemic agent clinically available" [1,2]. It is therefore not surprising to note that as both the incidence and prevalence of T2DM globally rise, alongside increasing life expectancy and longer duration of chronic disease, the use of insulin in the management of T2DM has continued to increase over the past 2 decades with over $30 \%$ of people with T2DM currently on it [2]. Insulin improves glycaemic control but is associated with weight gain and hypoglycaemia - known risk factors for CV diseases [3]. As insulin use in the management of diabetes rises, data on its CV outcomes have largely been inconsistent in both clinical trials and observational studies [4,5]. In view of the controversial publication on the adverse cardiovascular events induced by rosiglitazone [6], the American Food and Drug Administration and Control (FDA) in 2008 mandated that, before approval of any new antidiabetic therapy, CVOTs should be carried on all GLTs in order to demonstrate their CV benefits or risks [7]. Post-hoc analyses and epidemiological follow-up studies of these trials, in some cases, have either validated or refuted earlier study outcomes, making one to ponder if it is too early to conclude on the outcomes of most CVOTs.

\section{CVOTs vs. Post-hoc analyses/Epidemiological Follow-} up Studies

Why has this "most potent anti-hyperglycaemic agent" not been solely subjected to CVOT? With the exception of DEVOTE, and the ORIGIN trials, most CVOTs failed to compare only insulin with another GLT. Whilst earlier prospective trails as The United Kingdom Prospective Diabetes Study (UKPDS) [8], which compared insulin or sulphonylurea (intensive care) vs standard care showed reduction in the risk of microvascular event in the intensive glucose control arm but none for macrovascular events and all-cause mortality; Surprisingly, in a post hoc analysis (after a follow-up duration of 16.8 years), a $15 \%$ reduction in the risk of MI ( $p=0.01$ ) was observed in the intensive arm (Table 1).

In DIGAMI 1, [9] intensive insulin infusion was associated with a $28 \%$ reduction in all-cause mortality which was later confirmed in a 20-year post follow-up study which showed longer survival in the insulin (7.0 vs 4.1years) vs. conventional groups[10]; but DIGAMI 2 trial [11] failed to show any benefit. Another landmark trial, the ACCORD study [12] was prematurely terminated due to excess mortality (up to $35 \%$ ) in the intensive arm of the trial (95\%CI: 1.04-1.76). While it was also believed that the risks of hypoglycaemia and weight gain (in excess of $10 \mathrm{~kg}$ ) which were higher in the intensive arm could have driven this, a post hoc analysis on the association between hypoglycaemia and increased mortality showed that hypoglycaemia was associated with excess mortality in both arms. Also, in people who had just a single episode of severe hypoglycaemia, the risk of deaths was lower in the intensive arm [13], implying that hypoglycaemia may not have accounted for the excess mortality recorded. To explore the possible likely reasons, another post hoc analysis among all the trial participants showed that those with baseline HbA1c levels greater than $8.5 \%$ had a $65 \%$ increased risk of deaths. Coincidentally, these participants were found to be in the intensive therapy arm and did not have an improved HbA1c levels (HbA1c < 7\%) throughout the trial. Also, unlike in the standard care arm, $1 \%$ increase in HbA1c in the intensive therapy arm was associated with a $66 \%$ greater risk of mortality thereby suggesting that factors which are associated with the persistence of high HbA1c may have driven the excess mortality seen in this arm [14].

However, the ADVANCE trial [15] showed significant reductions in the risks of microvascular diseases in the intensive arm, but none 
for macrovascular events; all-cause mortality and CV deaths even after epidemiological follow up.

The ORIGIN Trial [16] showed no statistically significant difference in a 3-point composite of MI, stroke and CV death or a 5-point composite which included hospitalisation for $\mathrm{HF}$ and revascularisation for $\mathrm{CV}$ death signalling a turning point on the concerns around the use of insulin and was able to douse the concerns raised on its cardiovascular safety.

Table 1: Summary of outcomes of major CVOTs involving insulin and results of epidemiological follow-up and post hoc analyses.

\begin{tabular}{|c|c|c|c|c|c|c|}
\hline \multirow[b]{2}{*}{ Study } & \multicolumn{3}{|c|}{ Study Outcomes } & \multicolumn{3}{|c|}{ Epidemiological Follow-Up/Post Hoc Analyses } \\
\hline & $\begin{array}{l}\text { Microvascular } \\
\text { Outcomes }\end{array}$ & $\begin{array}{l}\text { Macrovascular } \\
\text { Outcomes }\end{array}$ & $\begin{array}{l}\text { Effect on } \\
\text { Mortality }\end{array}$ & $\begin{array}{l}\text { Microvascular } \\
\text { Outcomes }\end{array}$ & $\begin{array}{l}\text { Macrovascular } \\
\text { Outcomes }\end{array}$ & $\begin{array}{l}\text { Effect on } \\
\text { Mortality }\end{array}$ \\
\hline UKPDS & $\begin{array}{l}\text { Reduced microvascular } \\
\text { endpoint }\end{array}$ & No effect on MI* & None & $\begin{array}{l}\text { Reduced } \\
\text { microvascular } \\
\text { disease }\end{array}$ & Reduced MI & Reduced mortality \\
\hline DIGAMI-1 & Not available & Not available & Reduced mortality & Not available & Not available & Reduced mortality \\
\hline ACCORD & $\begin{array}{l}\text { Reduced retinopathy, } \\
\text { nephropathy, } \\
\text { neuropathy }\end{array}$ & No effect on MACE** & Increased mortality & $\begin{array}{l}\text { Reduced } \\
\text { retinopathy }\end{array}$ & No effect on MACE & $\begin{array}{l}\text { No longer } \\
\text { increased }\end{array}$ \\
\hline ADVANCE & Reduced nephropathy & No effect on MACE & None & $\begin{array}{l}\text { Reduced end-stage } \\
\text { renal disease }\end{array}$ & No effect on MACE & None \\
\hline VADT & $\begin{array}{c}\text { Reduced progression of } \\
\text { albuminuria }\end{array}$ & No effect on MACE & None & Not available & Reduced MACE & None \\
\hline ORIGIN & No effect & No effect on MACE & None & Not available & Not available & Not available \\
\hline \multicolumn{7}{|c|}{ *MI: Myocardial infarction } \\
\hline & & **MACE: $\mathrm{M}$ & or Adverse Cardiovas & ular Events & & \\
\hline
\end{tabular}

Source: Adapted from Fisher [17].

\section{Is Insulin Now Safe?}

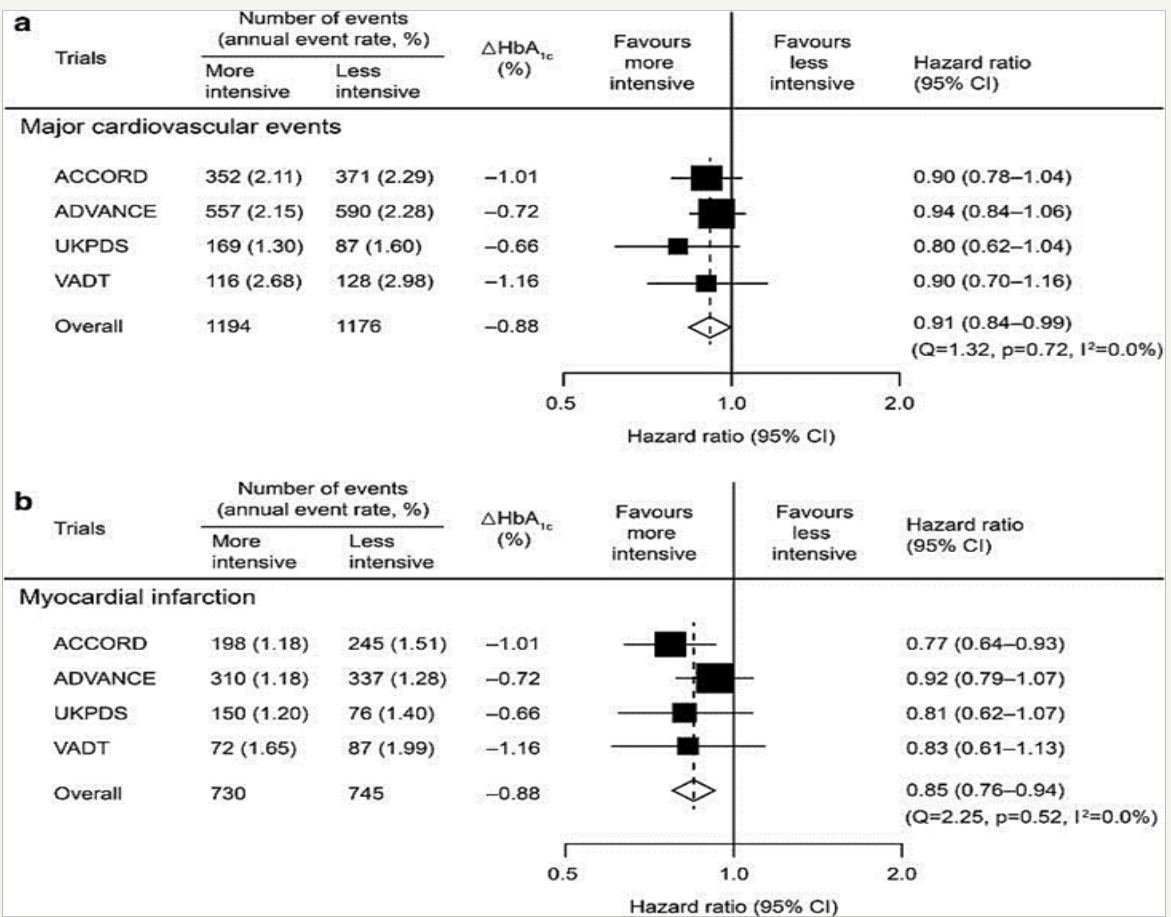

Figure 1: The effects of intensive versus standard glycemic control on (a) major cardiovascular events (CV death or non-fatal MI or non-fatal stroke) and (b) MI (fatal or non-fatal).

(ACCORD Action to Control Cardiovascular Risk in Diabetes, ADVANCE Action in Diabetes and Vascular Disease: Preterax and Diamicron MR Controlled Evaluation, CI confidence interval, CV cardiovascular, HbA1c glycated hemoglobin, MI myocardial infarction, UKPDS United Kingdom Prospective Diabetes Study, VADT Veteran Affairs Diabetes Trial) Source: Turnbull et al. [19]. 
From the above, it can be easily deduced that insulin, being part of the intensive control arm of the UKPDS, ACCORD, ADVANCE, VADT and ORIGIN trials did not to show any clear risk for major CV events compared to conventional therapy $[8,12,15,17,18]$ after long-term follow-up or post-hoc analyses. In spite of the excess mortality recorded by ACCORD study, it still showed significant reductions in microvascular complications alongside the UKPDS $[8,12]$. Similarly, the ADVANCE study showed a reduction in the risk of composite macro- and microvascular events but failed to show any other CV benefit [15] while DIGAMI trial showed no significant benefit with intensive care on all-cause mortality $[9,10]$.

This evidence was later made clearer in a meta-analysis of the 27,049 participants in the ACCORD, ADVANCE, UKPDS and VADT trials [19] which showed a 9\% reduction (HR: 0.91, 95\%CI: 0.840.99) in the risk of major CV events in the intensive therapy group compared to standard care (Figure 1). Nonetheless, this is believed to have been driven, to a large extent, by the $15 \%$ reduction in the risk of MI in these populations because no similar significant beneficial effects were reported for stroke, CV deaths or heart failure [19-21].

Currently, there is no meta-analysis of these trials which included the findings of the ORIGIN study. As stated above, the ORIGIN was the first CVOT which compared only insulin vs others, and whose primary outcome was CV events. In this large trial, 12,537 participants with CV risk factors were randomised to either once daily injection of insulin glargine or standard care (lifestyle modification, and/or metformin and/or sulfonylurea). Therefore, with the inclusion of the ORIGIN trial (see Figure 2), I have been able to show that the overall effect remained slightly non-significantly changed as the risk of major $\mathrm{CV}$ event was only slightly reduced from 9 to 5\% (HR: 0.95, 95\%CI: $0.88-1.03$ ).

\begin{tabular}{|c|c|c|c|c|c|c|c|}
\hline \multirow[b]{2}{*}{ Study or Subgroup } & \multicolumn{2}{|c|}{ Intensive } & \multicolumn{2}{|c|}{ Conventional } & \multirow[b]{2}{*}{ Weight } & \multirow{2}{*}{$\begin{array}{c}\text { Odds Ratio } \\
\text { IV, Random, } 95 \% \mathrm{Cl}\end{array}$} & \multirow{2}{*}{$\begin{array}{c}\text { Odds Ratio } \\
\text { IV, Random, } 95 \% \mathrm{Cl}\end{array}$} \\
\hline & Events & Total & Events & Total & & & \\
\hline ACCORD & 352 & 5128 & 386 & 5123 & $20.3 \%$ & $0.90[0.78,1.05]$ & $\rightarrow$ \\
\hline ADVANCE & 557 & 5571 & 590 & 5569 & $27.2 \%$ & $0.94[0.83,1.06]$ & \\
\hline ORIGIN & 1041 & 6264 & 1013 & 6273 & $37.5 \%$ & $1.03[0.94,1.14]$ & \\
\hline UKPDS & 169 & 2729 & 87 & 1138 & $7.6 \%$ & $0.80[0.61,1.04]$ & \\
\hline VADT & 116 & 899 & 126 & 892 & $7.4 \%$ & $0.90[0.69,1.18]$ & 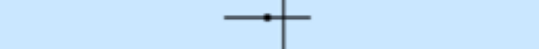 \\
\hline Total (95\% Cl) & & 20591 & & 18995 & $100.0 \%$ & $0.95[0.88,1.03]$ & \\
\hline Total events & 2235 & & 2202 & & & & \\
\hline $\begin{array}{l}\text { Heterogeneity: Tau } \\
\text { Test for overall effect }\end{array}$ & $\begin{array}{l}0.00 ; \mathrm{Chi}^{\prime} \\
\mathrm{Z}=1.27\end{array}$ & $\begin{array}{l}=5.21 \\
=0.21\end{array}$ & $d f=4(P$ & $=0.27) ; \mathrm{I}$ & $P^{2}=23 \%$ & & $\begin{array}{cccc}1 & 1 & 1 & 1 \\
0.2 & 0.5 & 1 & 2 \\
& \text { Favours Intensive } & \text { Favours Conventional }\end{array}$ \\
\hline
\end{tabular}

Figure 2: The effects of intensive versus standard glycaemic control on major cardiovascular events (CV death or non-fatal MI or non-fatal stroke) including the ORIGIN Trial [18].

\section{If No Harm, Why No Clear CV Benefit?}

Why did these trials fail to report any clear CV benefit? Possible explanations come to mind: first, there was lack of concordance between these trails evidenced by the following:

Firstly, the different follow-up periods: the mean follow-up duration in ACCORD was 3.5years while the median/mean followup durations for ORIGIN, UKPDS, ADVANCE, DIGAMI and VADT trials were $6.2,10.0,5,2.1$ and 5.6 years respectively. The short follow up duration in some trials could not have been enough to explore the biological plausibility of the outcomes recorded. Secondly, there were variations in the study populations e.g. the duration of diabetes ranged from zero in UKPDS to up to 10 years in ACCORD and VADT. Thirdly, the presence of other comorbidities and risk factors differed in these populations. For instance, 32\% of the ADVANCE trial study population had CV disease at the background, $40 \%$ in VADT, and 35\% in ACCORD; while more than half of the participants (58.8\%) in ORIGIN. Fourthly, there were minor variations in age (range: 53.3 to 66 years) and use of other non-GLTs. In addition to this, the target outcomes in these trials were non-individualised. As the management of diabetes evolves and becomes more individualised and patient-centred, these trials (as at the time they were conducted) were unable to take into account individual variations and unmet needs in treatment. In addition to this, there was the lack of consideration on the different mechanisms of action of the GLTs beside their already known effects on glucose control.

Finally, there was lack of uniformity or consensus on what constitutes the intensive and standard therapy arms of these trials; differences in the definition of the primary outcome and its components; differences in criteria for allocation to a treatment regimen [2,21-24]. In summary, judging by the proportion of patients with background CV diseases in these trials, it was thought this could have influenced the effect of intensive therapy. To explore this, a sub-study of VADT showed that intensive glycaemic control was associated with reduced CV events in those with no background history of CV (e.g. atherosclerosis) [25]. This implied that early initiation of intensive therapy in those with no CV history was associated improved CV outcomes.

This was supported by Turnbull et al. [19] in a meta-analysis of ACCORD, ADVANCE, UKPDS and VADT trials, showed a significant benefit in major $\mathrm{CV}$ events in the intensive therapy arm in those without a background $\mathrm{CV}$ diseases and shorter duration of diabetes (HR: 0.84, 95\% CI: 0.75 - 0.94) vs those with CV diseases and longer duration of diabetes (HR: 1.0, 95\% CI: $0.89-1.13$ ). Perhaps, more 
importantly, a sub-analysis on the ACCORD study by Riddle et al. showed that mortality outcome increased in patients whose HbA1c levels increased despite allocation to the intensively controlled arm. This suggests that factors like insulin resistance (obesity as a surrogate marker) may have also played an important role.

\section{References}

1. Triggle CR, Ding H (2014) Cardiovascular impact of drugs used in the treatment of diabetes. Ther Adv Chronic Dis 5(6): 245-268.

2. Alvarez CA, Lingvay I, Vuylsteke V, Koffarnus RL, McGuire DK (2015) Cardiovascular Risk in Diabetes Mellitus: Complication of the Disease or of Antihyperglycemic Medications. Clin Pharmacol Ther 98(2): 145-161.

3. Mannucci E, Dicembrini I, Lauria A, Pozzilli P (2013) Is Glucose Control Important for Prevention of Cardiovascular Disease in Diabetes? Diabetes Care 36(Supplement 2): S259-S263.

4. Currie CJ, Peters JR, Tynan A, Evans M, Heine RJ, et al. (2010) Survival as a function of $\mathrm{HbA1c}$ in people with type 2 diabetes: a retrospective cohort study. Lancet 375(9713): 481-489.

5. Roumie CL, Greevy RA, Grijalva CG, Hung AM, Griffin MR, et al. (2014) Association Between Intensification of Metformin Treatment With Insulin vs Sulfonylureas and Cardiovascular Events and All-Cause Mortality Among Patients With Diabetes. JAMA 311(22): 2288-2296.

6. Nissen SE, Wolski K (2007) Effect of rosiglitazone on the risk of myocardial infarction and death from cardiovascular causes. $\mathrm{N}$ Engl J Med 356(24): 2457-2471.

7. The Food and Drug Administration (2008) Guidance for industry diabetes mellitus-evaluating cardiovascular risk in new antidiabetic therapies to treat type 2 diabetes. In: U.S. Department of Health, Human Services Food and Drug Administration CfDEaRC (Eds.), New Hampsire, USA.

8. (1998) Intensive blood-glucose control with sulphonylureas or insulin compared with conventional treatment and risk of complications in patients with type 2 diabetes (UKPDS 33). UK Prospective Diabetes Study (UKPDS) Group. Lancet 352(9131): 837-853.

9. Malmberg K, Rydén L, Efendic S, Herlitz J, Nicol P, et al. (1995) Randomized trial of insulin-glucose infusion followed by subcutaneous insulin treatment in diabetic patients with acute myocardial infarction (DIGAMI study): Effects on mortality at 1 year. J Am Coll Cardiol 26(1): 57-65.

10. Malmberg K, Ryden L, Wedel H, Birkeland K, Bootsma A, et al. (2005) Intense metabolic control by means of insulin in patients with diabetes mellitus and acute myocardial infarction (DIGAMI 2): effects on mortality and morbidity. Eur Heart J 26(7): 650-661.

11. Ritsinger V, Malmberg K, Martensson A, Ryden L, Wedel H, et al. (2014) Intensified insulin-based glycaemic control after myocardial infarction: mortality during 20 year follow-up of the randomised Diabetes Mellitus
Insulin Glucose Infusion in Acute Myocardial Infarction (DIGAMI 1) trial. Lancet Diabetes Endocrinol 2(8): 627-633.

12. Gerstein HC, Miller ME, Byington RP, et al. (2008) Effects of intensive glucose lowering in type 2 diabetes. N Engl J Med 358(24): 2545-2559.

13. Bonds DE, Miller ME, Bergenstal RM, Buse JB, Byington RP, et al. (2010) The association between symptomatic, severe hypoglycaemia and mortality in type 2 diabetes: retrospective epidemiological analysis of the ACCORD study. BMJ 340: b4909.

14. Riddle MC, Ambrosius WT, Brillon DJ, Buse JB, Byington RP, et al. (2010) Epidemiologic relationships between $\mathrm{A} 1 \mathrm{C}$ and all-cause mortality during a median 3.4-year follow-up of glycemic treatment in the ACCORD trial. Diabetes Care 33(5): 983-990.

15. Patel A, MacMahon S, Chalmers J, Neal B, Billot L, et al. (2008) Intensive blood glucose control and vascular outcomes in patients with type 2 diabetes. N Engl J Med 358(24): 2560-7297.

16. ORIGIN Trial Investigators, Gerstein HC, Bosch J, Dagenais GR, Díaz R, et al. (2012) Basal Insulin and Cardiovascular and Other Outcomes in Dysglycemia. N Engl J Med 367(4): 319-328.

17. Fisher M (2016) Is diabetes still a state of premature cardiovascular death? Practical Diabetes 33(8): 261 -296.

18. Duckworth W, Abraira C, Moritz T, Reda D, Emanuele N, et al. (2009) Glucose control and vascular complications in veterans with type 2 diabetes. N Engl J Med 360(2): 129-139.

19. Turnbull FM, Abraira C, Anderson RJ, Byington RP, Chalmers JP, et al. (2009) Intensive glucose control and macrovascular outcomes in type 2 diabetes. Diabetologia 52(11): 2288-2298.

20. Guillausseau PJ, Virally M, Kevorkian JP, et al. (2009) Intensive blood suger control in type 2 diabetes: Results of recent interventional trials (ADVANCE, VA Diabetes Trial and ACCORD).

21. Dailey G, Wang E (2014) A Review of Cardiovascular Outcomes in the Treatment of People with Type 2 Diabetes. Diabetes Ther 5(2): 385-402.

22. Ray KK, Seshasai SRK, Wijesuriya S, Sivakumaran R, Nethercott S, et al. (2009) Effect of intensive control of glucose on cardiovascular outcomes and death in patients with diabetes mellitus: a meta-analysis of randomised controlled trials. Lancet 373(9677): 1765-1772.

23. Rensing KL, Reuwer AQ, Arsenault BJ, von der Thüsen JH, Hoekstra JB, et al. (2011) Reducing cardiovascular disease risk in patients with type 2 diabetes and concomitant macrovascular disease: can insulin be too much of a good thing? Diabetes Obes Metab 13(12): 1073-1087.

24. Holman RR, Sourij H, Califf RM (2014) Cardiovascular outcome trials of glucose-lowering drugs or strategies in type 2 diabetes. Lancet 383(9933): 2008-2017.

25. Reaven PD, Moritz TE, Schwenke DC, Anderson RJ, Criqui M, et al. (2009) Intensive glucose-lowering therapy reduces cardiovascular disease events in veterans affairs diabetes trial participants with lower calcified coronary atherosclerosis. Diabetes 58(11): 2642-2648.
Creative Commons Attribution 4.0 International License

For possible submissions Click Here

\section{Submit Article}

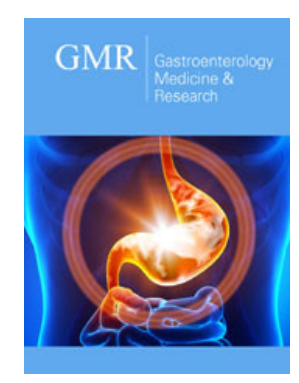

\section{Gastroenterology Medicine \& Research}

\section{Benefits of Publishing with us}

- High-level peer review and editorial services

- Freely accessible online immediately upon publication

- Authors retain the copyright to their work

- Licensing it under a Creative Commons license

- Visibility through different online platforms 